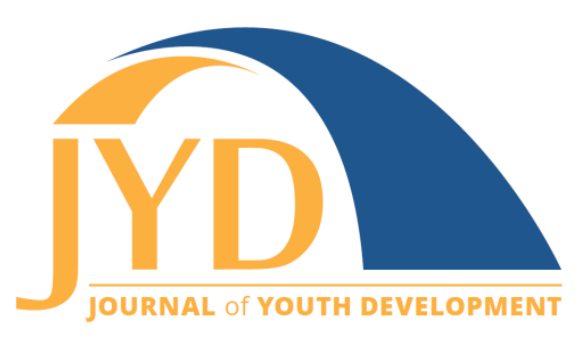

http://jyd.pitt.edu/ | Vol. 16 Issue 5 DOI 10.5195/jyd.2021.1096 | ISSN 2325-4017 (online)

\title{
Examining the Knowledge, Skills, and Dispositions of 4-H Professionals Related to LGBTQ+ Youth
}

\author{
Maru Gonzalez \\ North Carolina State University, Agricultural and Human Sciences \\ mgonza22@ncsu.edu
}

\section{Alex Barker}

Duke University, Department of Psychiatry \& Behavioral Sciences

mm.barker998@gmail.com

\section{Megan Clarke}

Duke University, Department of Psychiatry \& Behavioral Sciences

megan.clarke@duke.edu

\section{Christy M. Byrd}

North Carolina State University, Teacher Education and Learning Sciences

cmbyrd3@ncsu.edu

\section{Abstract}

Despite its status as the largest youth-serving organization in the United States, there is a dearth of empirical scholarship about LGBTQ+ youth within 4-H; research examining 4-H professionals' competencies to effectively support $\angle G B T Q+$ youth is even more scarce. To address this gap in the literature, this quantitative study explored the knowledge, skills, and dispositions of 4-H professionals in North Carolina as they relate to working with $L G B T Q+$ youth. Seventy-five professionals responded to an online survey. Professionals displayed higher levels of knowledge than skills or dispositions, were more knowledgeable about how to support $L G B$ youth compared to transgender and gender expansive youth, and expressed the need for and substantial interest in professional development. Rural professionals tended to report lower knowledge, skills, and dispositions compared to professionals working in urban/suburban settings. This article presents the study's findings and explores implications for future research and practice.

Key words: LGBTQ+ youth, 4-H, rural, youth development, transgender

(cc) EY New articles in this journal are licensed under a Creative Commons Attribution 4.0 License. This journal is published by the University Library System, University of Pittsburgh and is cosponsored by the University of Pittsburgh Press. The Journal of Youth Development is the official peer-reviewed publication of the National Association of Extension 4-H Youth Development Professionals and the National AfterSchool Association. 


\section{4-H Professionals and LGBTQ+ Youth}

\section{Introduction}

Over the span of more than two decades, activists, practitioners, and policy makers have called on schools and youth-serving organizations to adopt inclusive and affirming practices for working with youth who are lesbian, gay, bisexual, transgender, queer, or who hold an identity that does not conform to dominant social norms related to sexual orientation and gender identity ([LGBTQ+]; Gonzalez et al., 2020; Kokozos \& Gonzalez, 2020; Kosciw et al., 2020). Despite these efforts and significant social and legislative advancements for the LGBTQ+ community, LGBTQ+ young people continue to experience hostility and isolation at school (Kosciw et al., 2020), at home (Bregman et. al, 2013; Morton et al., 2018), and within their communities (Fish et al., 2019; Katz-Wise \& Hyde, 2012). The cumulative consequences of these experiences can be dire. Indeed, research has demonstrated that LGBTQ+ youth are more vulnerable than non-LGBTQ+ youth to depression, anxiety, stress, suicide, and drug and alcohol abuse (Goldbach et al., 2014; Katz-Wise \& Hyde, 2012; McLaren, 2009; Russell \& Fish, 2016).

LGBTQ+ young people living in rural communities often face even greater obstacles and increased risk factors, including fewer supportive adults, higher rates of discrimination, socially conservative gender and sexuality norms, and less access to affirming resources and community organizations (Barefoot et al., 2015; Gonzalez, 2016; O'Connell et al., 2010; Palmer et al., 2012). Research has also found that educators in rural communities have a more negative perception of lesbian, gay, and bisexual (LGB) students than any other marginalized student population (O'Connell et al., 2010). All of these factors may exacerbate feelings of alienation and isolation for LGBTQ+ youth in rural areas. Such conditions pose challenges for rural educators who are supportive of LGBTQ+ youth as well. For example, a study by Gonzalez (2016) found that rural school counselors who advocate for and with LGBTQ+ students may experience less administrative support and often have to navigate religion-based resistance from colleagues and community members.

Despite such daunting statistics, there is reason to be hopeful. A vast body of scholarship has demonstrated that affirming environments and an increased sense of belonging are linked to positive academic, social, and emotional outcomes among LGBTQ+ youth, including higher selfesteem, psychological well-being, and academic success (Barr et al., 2016; Kosciw et, al, 2020; Wong et al., 2014). Having adults in school settings—such as teachers and school staff-who support the LGBTQ+ identities of youth is linked to more positive mental wellbeing, stronger feelings of safety, and better academic engagement and outcomes among LGBTQ+ youth (Johns et al., 2019; Kosciw et al., 2020; Seelman et al., 2015). Further, when adults in school 


\section{4-H Professionals and LGBTQ+ Youth}

settings display their support by intervening effectively in incidents of anti-LGBTQ+ bullying and harassment, LGBTQ+ students report fewer experiences of harassment and assault and fewer days of school missed (Johns et al., 2019; Kosciw et al., 2020).

Professional development of educators and youth-serving professionals is key to developing the knowledge and skills needed to work effectively with LGBTQ+ young people (Bradley et al., 2019; Doellman, 2017). Nevertheless, many educators have not participated in LGBTQ+ youthrelated training and are therefore not adequately prepared to support this population competently and proactively (Goodrich \& Luke, 2010 Gonzalez, 2016; McCabe et al., 2013), particularly as it relates to having the skills to appropriately interact with LGBTQ+ youth and intervene when necessary (Farmer et al., 2013). Professional development inclusive of and specific to serving the needs of transgender, intersex, and gender expansive young people appears to be even more scarce (Kearns et al., 2017; Marx et al., 2017; Simons et al., 2018), further isolating this demographic. Notably, educators who have received training related to LGBTQ+ youth have shown increased preparedness and confidence in advocating for and with LGBTQ+ young people (Bradley et al., 2019; Gonzalez, 2016).

\section{4-H and the Benefits of Positive Youth Development}

While the vast majority of scholarship on the impact of affirming environments on LGBTQ+ youth has been conducted in K-12 settings (Gonzalez, 2017; Hatchel et al., 2018, Kosciw et al., 2020), scholarship related to community- and youth-serving organizations has consistently underscored the social and emotional benefits of supportive and inclusive settings on LGBTQ+ youth (Diaz \& Kosciw, 2011; Fish et al., 2019; Williams; et al., 2019). As the country's largest youth development organization, $4-\mathrm{H}$ is a leader in cultivating young people's strengths and leadership capacities in urban, suburban, and rural communities in every state across the nation. Nevertheless, there is a dearth of conceptual scholarship-and virtually no empirical research-related to LGBTQ+ youth within 4-H and the professionals who work with them (Gonzalez et al., 2020; Soule, 2017).

As an organization, 4- $\mathrm{H}$ is grounded in a positive youth development (PYD) framework, a strengths-based approach to youth development that guides schools and community-serving organizations in ensuring that young people can reach their full potential (Larson, 2000; Lerner et al., 2005). While the PYD model assumes all young people are capable of success, it also recognizes the valuable role of supportive adults and affirming, connected, and caring environments in contributing to youth thriving (Benson et al., 2011; Lerner et al., 2005). Such an assumption is particularly relevant to LGBTQ+ youth populations, who often receive less support than their heterosexual, cisgender peers across school, community, and familial 


\section{4-H Professionals and LGBTQ+ Youth}

contexts (Fish et al., 2019; Gonzalez, 2017; Hatchel et al., 2018, Ryan et al., 2010). Despite 4-H's documented benefits in building youth's strengths and resilience through PYD programming, there exists a gap in both research and practice as it relates to 4-H's impact on LGBTQ+ young people specifically.

In response, youth development scholars have underscored the need for additional research and have called on 4- $\mathrm{H}$ programs and practices to be more deliberate and proactive about cultivating a climate in which LGBTQ+ youth feel affirmed and supported while ensuring that 4-H professionals possess the professional development necessary to best engage LGBTQ+ young people (Gonzalez et al., 2020; McKee \& Bruce, 2019; Soule, 2017). In order to heed these calls to action and begin addressing these gaps in both scholarship and practice, the purpose of this research is to explore the knowledge, skills, and dispositions of 4- $\mathrm{H}$ professionals in North Carolina relative to working effectively with LGBTQ+ young people, with the ultimate aim of better serving LGBTQ+ youth through the development of resources and recommendations for professional development within $4-\mathrm{H}$.

\section{Research Questions and Hypotheses}

Our research questions were as follows:

1. What knowledge, skills, and dispositions do 4-H professionals report?

a. How is previous training associated with knowledge, skills, and dispositions?

2. How supported do 4-H professionals feel creating welcoming and affirming environments for and with LGBTQ+ youth?

a. How is perceived support for creating welcoming and affirming environments associated with knowledge, skills, and dispositions?

3. How do professionals in rural settings differ from professionals in urban/suburban settings?

For RQ1 (What knowledge, skills, and dispositions do 4-H professionals report?), we had a number of hypotheses. We expected that 4-H professionals would score higher on indicators measuring knowledge than those measuring skills. We also hypothesized that professionals would display more knowledge and skills related to sexual orientation (i.e., LGB youth) than gender identity and sex assigned at birth (i.e., transgender, gender expansive, and intersex youth). In terms of dispositions, we hypothesized that professionals would score higher on disposition indicators related to general acceptance of LGBTQ+ youth and need for training but lower on disposition indicators related to making structural program changes, such as ensuring that 4-H dances are LGBTQ+-affirming or allowing youth to use bathroom facilities according to their gender identity. Finally, specific to RQ1a, we hypothesized that professionals who had 


\section{4-H Professionals and LGBTQ+ Youth}

attended training would have higher scores for knowledge and skills, in line with previous research findings (Bradley et al., 2019; Gonzalez, 2016). However, given the wide variation of training available about serving LGBTQ+ youth-including the time, depth, and objectives of such training-we did not anticipate a significant difference in dispositions between those who had and had not attended training.

For RQ2 (How supported do professionals feel creating welcoming and affirming environments for and with LGBTQ+ youth, and how is perceived support associated with knowledge, skills, and dispositions?), we hypothesized that perceived support would be correlated with knowledge and skills. Specifically, we hypothesized that professionals with higher perceived support would display more knowledge and would report more application of skills related to creating welcoming and affirming environments for LGBTQ+ youth.

For RQ3 (How do professionals in rural settings differ from professionals in urban/suburban settings?), we hypothesized that professionals in rural settings would score lower on indicators measuring knowledge, skills, and dispositions. Related, we also anticipated that professionals in rural settings would report lower perceived support for creating welcoming and affirming environments for LGBTQ+ youth. These hypotheses were based on previous research finding more socially conservative gender and sexuality norms in rural settings as well as lower levels of access in rural communities to local LGBTQ+ specific resources and community organizations (Barefoot et al., 2015; Gonzalez, 2016; O'Connell et al., 2010; Palmer et al., 2012). All of these barriers can impact the degree to which rural professionals have access to professional development opportunities and feel equipped and supported to work with LGBTQ+ youth.

\section{Methods}

\section{Participants}

Participants included 75 youth development professionals in North Carolina 4-H. In terms of age, $26.7 \%$ were between the ages of 18 and $30,20 \%$ were between the ages of 31 and 38 , $30 \%$ were 39 to 50 , and $23.4 \%$ were over the age of 50 . Of the 75 professionals who responded to the survey, $26 \%$ worked in counties designated by the North Carolina Rural Center (n.d.) as urban or regional city/suburban and $74 \%$ worked in rural counties. To preserve anonymity, participants were not asked to indicate any additional demographic information or professional title(s). 


\section{4-H Professionals and LGBTQ+ Youth}

\section{Procedure and Measures}

An anonymous online survey and two subsequent email reminders were sent to all North Carolina 4-H employees through the employee listserv. The survey response rate was $40 \%$, took about 5 to 10 minutes to complete, and participants were not compensated. The survey was developed by youth development and child mental health scholars and practitioners with combined lived and professional experience related to LGBTQ+ issues across rural, suburban, and urban contexts.

This study focused on Extension professionals' knowledge of LGBTQ+ youth and related issues, their skills for supporting LGBTQ+ youth and cultivating an LGBTQ+ affirming environment, and their general disposition or attitude toward LGBTQ+ youth. Our conceptualization of knowledge, skills, and dispositions for working with LGBTQ+ youth was informed by Brown and Trusty's Advocacy Competencies (2005), in which they define effective advocacy-including with LGBTQ+ youth-as possessing advocacy knowledge; demonstrating advocacy skills; and having a disposition toward advocacy, one that is shaped by personal values and beliefs. Further explanation of these constructs, including definitions and corresponding indicators, are included in Table 1.

Drawing on Brown \& Trusty's model (2005), knowledge was defined as the extent to which professionals were familiar with the needs and experiences of LGBTQ+ youth, as well as terminology, issues, and resources specific to the LGBTQ+ community. Knowledge of terms was assessed with eight items on a scale of 1 ( $I$ have not heard this term before) to 4 ( $I$ am completely confident that I know what this term means) and five items on a separate scale of 1 (strongly agree) to 4 (strongly disagree).

Skills were defined as the appropriate application of knowledge to support LGBTQ+ youth and cultivate an environment that is affirming and welcoming to LGBTQ+ individuals, and dispositions were defined as general attitudes toward LGBTQ+ youth (Brown \& Trusty, 2005). Skills and dispositions were assessed with 19 items on response scales of 1 (strongly agree/always) to 4 (strongly disagree/never) and 1 (often/very interested) to 3 (never/not interested), and one yes/no question. 
Table 1. Knowledge, Skills, and Dispositions as Applied to LGBTQ+ Youth

\begin{tabular}{|c|c|c|}
\hline Construct & Definition & Indicators \\
\hline Knowledge & $\begin{array}{l}\text { The extent to which one is familiar } \\
\text { with the needs and experiences of } \\
\text { LGBTQ+ youth, as well as } \\
\text { terminology, issues, and resources } \\
\text { specific to the LGBTQ+ community }\end{array}$ & $\begin{array}{l}\text { - Knowledge of terminology and concepts } \\
\text { - Knowledge of resources } \\
\text { - Knowledge of protocols and standards of } \\
\text { practice }\end{array}$ \\
\hline Skills & $\begin{array}{l}\text { The appropriate application of } \\
\text { knowledge to support LGBTQ+ youth } \\
\text { and cultivate an environment that is } \\
\text { welcoming to LGBTQ+ individuals }\end{array}$ & $\begin{array}{l}\text { - Communication skills } \\
\text { - Problem assessment and solving skills } \\
\text { - Interpersonal advocacy skills } \\
\text { - Skills for delivering affirming and } \\
\text { inclusive programming } \\
\text { - Program/organizational-level advocacy } \\
\text { skills } \\
\text { - Collaboration skills }\end{array}$ \\
\hline Dispositions & $\begin{array}{l}\text { One's general attitude toward } \\
\text { LGBTQ+ youth }\end{array}$ & $\begin{array}{l}\text { - Value for learning and training } \\
\text { Value for creating affirming and } \\
\text { welcoming environments }\end{array}$ \\
\hline
\end{tabular}

\section{Results}

Our first question was, "What knowledge, skills, and dispositions do 4-H professionals report?" First, the 4-H professionals were asked to indicate how familiar they were with a number of terms describing sexual orientation and gender identity. Means and standard deviations for respondents' familiarity with terms and resources are reported in Table 2.

The professionals were most familiar with the terms, "lesbian" and "gay," with $88 \%$ and $85 \%$, respectively, completely confident in their knowledge. The professionals were least familiar with the terms, "pansexual" and "intersex." Large percentages-19\% for pansexual and $28 \%$ for intersex-had not heard the terms before.

The professionals also rated their knowledge of the distinction between certain terms related to LGBTQ+ identity, with higher scores indicating lower knowledge. Professionals reported high levels of confidence in the difference between sex assigned at birth and gender identity, with $95 \%$ agreeing. In addition, they reported high levels of confidence in the difference between 
sexual orientation and gender identity, with $90 \%$ agreeing. Finally, professionals rated their familiarity with 4-H protocols and resources related to working with LGBTQ+ youth, with higher scores indicating lower knowledge. The professionals were least comfortable with knowing where to refer LGBTQ+ youth and their parents and caregivers for affirming resources. Only $42 \%$ and $44 \%$ of professionals strongly or somewhat agreed with these statements. The professionals were most comfortable with $4-\mathrm{H}$ non-discrimination protocols $(M=1.53, S D=$ $.68)$, with $90 \%$ agreeing.

Table 2. Means and Standard Deviations for Respondents' Reported Knowledge of Terms, and Agreement Level on Other Statements of Understanding

\begin{tabular}{|l|c|c|}
\hline Knowledge: Terms $^{\text {a }}$ & Mean & SD \\
\hline Lesbian & 3.88 & 0.324 \\
\hline Gay & 3.83 & 0.418 \\
\hline Bisexual & 3.83 & 0.378 \\
\hline Transgender & 3.63 & 0.581 \\
\hline Gender non-conforming & 2.93 & 0.888 \\
\hline Non-binary & 2.63 & 1.015 \\
\hline Pansexual & 2.53 & 1.040 \\
\hline Intersex & 2.23 & 1.015 \\
\hline Knowledge: Otherb & 1.36 & 0.689 \\
\hline I understand the difference between sex assigned at birth and gender identity. & 1.53 & 0.679 \\
\hline $\begin{array}{l}\text { I am familiar with 4-H protocols and standards of practice that include non- } \\
\text { discrimination protections on the basis of sexual orientation and gender identity. }\end{array}$ & 1.53 & 0.774 \\
\hline I understand the difference between sexual orientation and gender identity. & 2.20 & 0.886 \\
\hline I know where to access resources to increase my own knowledge of best practices to & & \\
\hline support LGBTQ+ youth. & 2.71 & 0.911 \\
\hline I know where to refer LGBTQ+ youth who request LGBTQ+ affirming resources. & 2.71 & 0.929 \\
\hline $\begin{array}{l}\text { I know where to refer parents and caregivers of LGBTQ+ youth who request } \\
\text { resources to better support their child(ren). }\end{array}$ & \\
\hline Respnse scale for knower & & \\
\hline
\end{tabular}

a Response scale for knowledge of terms: 1 (I have not heard this term before.) to 4 (I am completely confident that I know what this term means.)

${ }^{\mathrm{b}}$ Response scale for other knowledge: 1 (strongly agree) to 4 (strongly disagree) 
Next, professionals were asked to rate their level of agreement with statements about actions or behaviors used to create an affirming environment in their program, with higher scores indicating lower skill levels. The mean and standard deviation for respondents' ratings on each statement is reported in Table 3. They reported frequently using youths' indicated pronouns and discouraging anti-LGBTQ language and behavior. Only one person indicated that they would not use requested pronouns, and two people reported that they never talk to youth about how engaging in anti-LGBTQ+ language or actions could be harmful. However, the professionals less often included positive images of LGBTQ+ people in their programming or shared their own pronouns. Half (50\%) never included positive images of LGBTQ+ people and three quarters $(76 \%)$ never shared their pronouns during introductions.

Table 3. Means and Standard Deviations of Respondents' Ratings on Their Skills

\begin{tabular}{|c|c|c|}
\hline Skill statement ${ }^{a}$ & Mean & SD \\
\hline $\begin{array}{l}\text { If a youth tells me what pronouns they want me to use when referring to them, I will } \\
\text { consistently use those pronouns, even if they are different than the pronouns I have } \\
\text { used in the past. }\end{array}$ & 1.25 & 0.477 \\
\hline $\begin{array}{l}\text { If a student uses or engages in language or actions that are anti-LGBTQ+ during } \\
\text { programming, I talk with them about how that behavior could be harmful. }\end{array}$ & 1.71 & 0.872 \\
\hline $\begin{array}{l}\text { I avoid categorizing youth by gender during programming activities (e.g., "Boys on } \\
\text { this side of the room and girls on that side of the room"). }\end{array}$ & 2.15 & 0.887 \\
\hline $\begin{array}{l}\text { I work to avoid collaborating with organizations that communicate anti-LGBTQ+ } \\
\text { stances. }\end{array}$ & 2.40 & 1.193 \\
\hline $\begin{array}{l}\text { I review printed or multimedia materials for negative language associated with } \\
\text { LGBTQ+ identities prior to using them within my program. }\end{array}$ & 2.44 & 1.193 \\
\hline $\begin{array}{l}\text { If a colleague uses a term related to LGBTQ+ identity inaccurately and/or } \\
\text { offensively, I talk to them to educate them about the appropriate terminology. }\end{array}$ & 2.72 & 0.959 \\
\hline $\begin{array}{l}\text { I ask where and with whom LGBTQ+ youth are comfortable sharing their sexual } \\
\text { orientation or gender identity. }\end{array}$ & 3.07 & 1.168 \\
\hline $\begin{array}{l}\text { I actively seek out collaborators that provide LGBTQ+ supportive and specific } \\
\text { resources and programming. }\end{array}$ & 3.16 & 0.951 \\
\hline $\begin{array}{l}\text { I include examples and/or positive images of LGBTQ+ people, relationships, and } \\
\text { families in programming. }\end{array}$ & 3.26 & 0.890 \\
\hline I share my own pronouns during group introductions & 3.71 & 0.559 \\
\hline
\end{tabular}


Table 3. (continued)

\begin{tabular}{|c|c|c|}
\hline Skill statement ${ }^{a}$ & Mean & SD \\
\hline $\begin{array}{l}\text { If a youth tells me what pronouns they want me to use when referring to them, I will } \\
\text { consistently use those pronouns, even if they are different than the pronouns I have } \\
\text { used in the past. }^{\text {b }}\end{array}$ & 1.25 & 0.477 \\
\hline $\begin{array}{l}\text { If a student uses or engages in language or actions that are anti-LGBTQ+ during } \\
\text { programming, I talk with them about how that behavior could be harmful. }\end{array}$ & 1.71 & 0.872 \\
\hline $\begin{array}{l}\text { I avoid categorizing youth by gender during programming activities (e.g., "Boys on } \\
\text { this side of the room and girls on that side of the room"). }\end{array}$ & 2.15 & 0.887 \\
\hline $\begin{array}{l}\text { I work to avoid collaborating with organizations that communicate anti-LGBTQ+ } \\
\text { stances. }\end{array}$ & 2.40 & 1.193 \\
\hline $\begin{array}{l}\text { I review printed or multimedia materials for negative language associated with } \\
\text { LGBTQ+ identities prior to using them within my program. }\end{array}$ & 2.44 & 1.193 \\
\hline $\begin{array}{l}\text { If a colleague uses a term related to LGBTQ+ identity inaccurately and/or } \\
\text { offensively, I talk to them to educate them about the appropriate terminology. }\end{array}$ & 2.72 & 0.959 \\
\hline $\begin{array}{l}\text { I ask where and with whom LGBTQ+ youth are comfortable sharing their sexual } \\
\text { orientation or gender identity. }\end{array}$ & 3.07 & 1.168 \\
\hline $\begin{array}{l}\text { I actively seek out collaborators that provide LGBTQ+ supportive and specific } \\
\text { resources and programming. }\end{array}$ & 3.16 & 0.951 \\
\hline $\begin{array}{l}\text { I include examples and/or positive images of LGBTQ+ people, relationships, and } \\
\text { families in programming. }\end{array}$ & 3.26 & 0.890 \\
\hline I share my own pronouns during group introductions & 3.71 & 0.559 \\
\hline \multicolumn{3}{|l|}{ Skill demonstration ${ }^{c}$} \\
\hline $\begin{array}{l}\text { I talk with my co-workers about ways we can make 4-H more welcoming and } \\
\text { affirming for LGBTQ+ youth }\end{array}$ & 2.17 & 0.647 \\
\hline $\begin{array}{l}\text { I talk with 4-H leadership (at county, district, or state level) about ways we can make } \\
\text { 4-H more welcoming and affirming for LGBTQ+ youth. }\end{array}$ & 2.29 & 0.617 \\
\hline \multicolumn{3}{|l|}{ a Response scale for skill statements: 1 (always) to 4 (never) } \\
\hline \multicolumn{3}{|l|}{ b Response scale for this one skill statement was 1 (strongly agree) to 4 (strongly disagree) } \\
\hline c Response scale for skill demonstration: 1 (often) to 3 (never) & & \\
\hline
\end{tabular}

Finally, we asked the professionals about their disposition toward LGBTQ+ youth and steps they have taken, if any, to create a welcoming and affirming environment for them. Disposition statements and the response averages and standard deviations are reported in Table 4; again, higher scores indicated lower affirmation of dispositions. The professionals strongly believed 
that training about supporting LGBTQ+ youth was necessary for 4-H staff and that specific programs for LGBTQ+ youth were necessary. Furthermore, the professionals were interested in attending trainings. Only two individuals disagreed that training was important and were not interested in training. These two individuals were also the only ones who had not attended training and did not try to stay up to date on terminology. The professionals were divided on support for youth using bathrooms that matched their gender identity at 4-H events, with $63 \%$ strongly or somewhat agreeing.

\section{Table 4. Means and Standard Deviations of Respondents' Ratings on Their Dispositions}

\begin{tabular}{|l|c|c|}
\hline Dispositions: Level of agreement & Mean & SD \\
\hline $\begin{array}{l}\text { I believe that specific training about supporting LGBTQ+ youth is necessary for 4-H } \\
\text { staff in my role. }\end{array}$ & 1.36 & 0.550 \\
\hline $\begin{array}{l}\text { I believe that specific programs or actions to support LGBTQ+ youth specifically } \\
\text { are necessary as part of 4-H. }\end{array}$ & 1.69 & 0.815 \\
\hline \begin{tabular}{l} 
I believe that 4-H dances should affirm and include LGBTQ+ youth relationships. \\
\hline I try to continue learning up-to-date terminology related to LGBTQ+ youth.b
\end{tabular} & 1.75 & 0.801 \\
\hline $\begin{array}{l}\text { I believe that young people should be able to use the bathroom or locker room } \\
\text { that matches their gender identity while at 4-H events and programming, even if } \\
\text { their gender identity is different than the sex they were assigned at birth. }\end{array}$ & 2.12 & 0.873 \\
\hline $\begin{array}{l}\text { Dispositions: Level of interest } \\
\text { What is your level of interest in attending professional development trainings, }\end{array}$ & 1.030 \\
\hline $\begin{array}{l}\text { workshops, or conferences that specifically include information about how to best } \\
\text { support LGBTQ+ youth? }\end{array}$ & 1.46 & 0.567 \\
\hline $\begin{array}{l}\text { Dispositions: Yes/no } \\
\text { I display materials in my workspaces that are supportive of LGBTQ+ youth (e.g., } \\
\text { rainbow flags, LGBTQ+ affirming images or resources). }\end{array}$ & Yes: $11.9 \%$ \\
\hline $\begin{array}{l}\text { a Response scale for level of agreement: } 1 \text { (strongly agree) to 4 (strongly disagree) } \\
\text { c Response scale for this one item was 1 (always) to 4 (never). }\end{array}$ & \\
\hline
\end{tabular}

We were also interested in how training was associated with knowledge, skills, and dispositions. The professionals were asked if they had attended trainings, workshops, or conferences that included information on how to support LGBTQ+ youth, and $71 \%$ had, including $66.7 \%$ of rural professionals and $80 \%$ of urban/suburban professionals. T-tests with Bonferroni corrections 


\section{4-H Professionals and LGBTQ+ Youth}

revealed that those with training were more likely to know where to access resources to increase their own knowledge $(t(55)=-3.58, p=.001)$, as well as where to refer LGBTQ+ youth $(t=-3.40, p=.002)$ and parents $(t(55)=-3.32, p=.002)$ who request resources, which were the areas of lowest knowledge.

Our second research question asked professionals the extent to which they would be supported in efforts to create a more welcoming environment in their workplace: $22 \%$ strongly agreed with this statement, $40 \%$ somewhat agreed, $25.4 \%$ somewhat disagreed, and $11.9 \%$ strongly disagreed. We explored the extent to which perceived support was associated with professionals' knowledge, skills, and dispositions through bivariate correlations. There were positive relationships, though none of the correlations were significant after a Bonferroni correction. The strongest correlations with support were for believing specific programs or actions are necessary to support LGBTQ+ youth in 4-H $(r=.289, p=.03)$, actively seeking out collaborators that provide LGBTQ+ supportive and specific resources and programming ( $r=$ $.276, p=.04)$, and including examples and/or positive images of LGBTQ+ people, relationships, and families in their programming $(r=.329, p=.012)$.

Finally, we were interested in how rural professionals and settings differed from urban/suburban professionals and settings. Professionals were classified as "urban/suburban" if they indicated that they were located in a county which was designated by the North Carolina Rural Center (n.d.) as urban or regional city/suburban (26\%) and "rural" if they were located in a county without those designations (74\%). Using independent samples $t$-tests with an alpha level corrected to .002 due to multiple comparisons, we found that rural professionals scored lower than their urban counterparts in nearly all of the knowledge, skills, and dispositions and were significantly less likely to actively seek out collaborators who could provide resources and programming supportive and specific to LGBTQ+ youth $\left(M_{\text {Rural }}=3.51, S D=.71 ; M_{\text {urban }}\right.$ Suburban $=$ 2.33, $S D=.98 ; t=-4.95, p<.001$ ). Additionally, urban/suburban professionals anticipated significantly more support than rural professionals if they were to take steps to create a more welcoming environment $\left(M_{\text {Rural }}=2.50, \mathrm{SD}=.94 ; M_{\text {rban } / \text { Suburban }}=1.67, S D=.72 ; t(55)=-3.10\right.$, $p<.001)$.

\section{Discussion}

While there are growing calls for research focused on the experiences of LGBTQ+ youth within 4-H and the Extension professionals who work with them (Gonzalez et al., 2020; Soule, 2017), virtually no empirical scholarship exists that is specific to $4-\mathrm{H}$. This quantitative study investigated the knowledge, skills, and dispositions of North Carolina 4-H professionals as they 


\section{4-H Professionals and LGBTQ+ Youth}

relate to LGBTQ+ youth. Although participants demonstrated a broad range of knowledge, skills, and dispositions, we found several similarities in their responses. Overall, our findings align with each of our hypotheses, as well as existing research related to LGBTQ+ youth.

As we expected, professionals' knowledge level was higher than the skill levels they employed. For example, while most professionals reported high levels of confidence related to terminology, they were less likely to apply skills, such as including affirming images of LGBTQ+ people in their programming materials or sharing their personal pronouns. A study measuring counselor competence with LGB clients across practice settings yielded comparable results (Farmer et al., 2013). Specifically, school counselor participants reported the least competence in having the skills to effectively support the LGB students with whom they worked; in contrast, reported competence related to knowledge and dispositions was considerably higher. As anticipated and consistent with previous research (Gonzalez, 2017), findings revealed a tendency by professionals to be reactive in their support of LGBTQ+ youth-such as addressing discriminatory behavior-rather than proactive in their support through actions such as displaying LGBTQ+-affirming materials in their workspace.

We also hypothesized that professionals would score higher on disposition indicators related to general support for LGBTQ+ youth and the value of professional development but lower on disposition indicators about taking preventative measures or making structural program changes to foster a welcoming and affirming environment. As anticipated, findings showed strong agreement among professionals with more general statements such as the importance of training and programming specific to LGBTQ+ youth. However, there was relatively lower agreement about the need for structural program changes, such as ensuring that youth could use bathrooms matching their gender identity at 4-H events.

While the overwhelming majority of professionals agreed that supporting LGBTQ+ young people was essential to their role within 4-H, many demonstrated a lack of skills for effectively and proactively supporting transgender and gender expansive youth. For instance, the vast majority (i.e., 76\%) reported never modeling pronoun usage during introductions. Professionals were also split on whether they supported young people using bathrooms that aligned with their gender identity at 4-H events. These results, while disconcerting, are not surprising given the lack of training educators and youth-serving professionals receive relative to developing the knowledge and skills necessary for working with transgender, intersex, and gender expansive young people (Kearns et al., 2017; Marx et al., 2017; Simons et al., 2018). 


\section{4-H Professionals and LGBTQ+ Youth}

Notably, professional development played a role in determining the extent to which professionals had the knowledge and skills to effectively serve the needs of all LGBTQ+ young people, a finding consistent with existing literature (Bradley et al., 2019; Gonzalez, 2016). As we anticipated, professionals who had previously received training related to LGBTQ+ young people were more likely to have the skills to access LGBTQ+-affirming resources and refer LGBTQ+ young people and their caregivers who may be seeking additional support. Similarly, and as anticipated, professionals who expressed perceived support in potential efforts to foster a more welcoming environment demonstrated a higher degree of knowledge and skills relative to working with LGBTQ+ youth, such as seeking out collaborators to assist with identifying resources and developing programmatic efforts and including positive images of LGBTQ+ people in their programming.

Finally, rural professionals demonstrated less knowledge and fewer skills about LGBTQ+ people and had a less affirming disposition toward them than those working in urban/rural areas, a finding consistent with previous literature (O'Connell, 2010). Additionally, and as we hypothesized, rural professionals were less likely than their urban/suburban counterparts to expect support should they take steps to cultivate an environment more affirming of LGBTQ+ individuals. Literature in the field of education has yielded similar results (Gonzalez, 2016).

\section{Strengths and Limitations}

This study is the first of its kind within 4- $\mathrm{H}$ to assess the extent to which 4-H Extension professionals have the knowledge, skills, and dispositions to effectively support LGBTQ+ youth, making a significant contribution to the field. Our study included several added strengths that supported this research. First, although there was no incentive provided to $4-\mathrm{H}$ professionals who completed the survey, the results concluded a response rate of $40 \%$, meaning that these results reflect the knowledge, skills, and dispositions of almost half of all 4-H professionals across the state of North Carolina. Additionally, one of the greatest strengths incorporated in this project was the diversity of the research team. Two of the study's authors currently or have previously worked directly with 4- $\mathrm{H}$, one as a specialist and the other as a former 4- $\mathrm{H}$ professional with experience providing programming directly to youth on the county level. Additionally, the research team not only incorporated professionals with diverse knowledge and experience in education, youth development, and youth mental health, but also combined both lived and professional experiences with LGBTQ+ youth issues across rural, suburban, and urban contexts.

Several limitations exist within the survey itself. First, while the survey asked if professionals had attended professional development training, it did not uncover if professionals attended 


\section{4-H Professionals and LGBTQ+ Youth}

different types or levels of training related to supporting LGBTQ+ youth. The survey questions did not address intersectionality with other marginalized identities, and the terms used within the survey are not all-encompassing of the terms within the LGBTQ+ community. Additionally, some of the survey questions required some level of knowledge of terminology that not all respondents may have had, impacting their ability to fully respond. Lastly, there is a large void of existing research about LGBTQ+ youth in 4-H and in other community-based youth-serving organizations for this study to draw upon in conceptualization and design.

\section{Implications for Future Research and Practice}

This study shows the importance of increased professional development for 4-H professionals related to working with LGBTQ+ youth. Specifically, it reflects the need for professional development moving beyond terminology to focus specifically on skill development and application and proactive support, as well as professional development specific to working with transgender, intersex, and gender expansive youth. It also shows the value of ensuring increased access to training in rural communities. Finally, given the benefit of perceived support, professional development should be provided to all levels of 4- $\mathrm{H}$ staff, including leadership and administrative staff.

Extensive research is still needed regarding LGBTQ+ youth and best practices to support them through youth-serving organizations such as $4-\mathrm{H}$. Replicating this or a similar study with a larger and more geographically diverse sample size could yield more generalizable data regarding the knowledge, skills, and dispositions of $4-\mathrm{H}$ professionals, thereby making the case for a more comprehensive and formalized training and curriculum plan. Applying a qualitative or mixed methods design in future studies would also allow for more nuanced responses from 4-H professionals. Moreover, additional inquiry should be explored on the knowledge, skills, and dispositions of 4-H professionals as they relate to transgender, gender expansive, and intersex identities. Future research should also be replicated or expanded to include 4-H volunteers.

Research on the experiences of current and former LGBTQ+ young people who have participated in 4-H programming is also warranted, as it would assist in painting a more comprehensive picture of the climate for LGBTQ+ youth within 4-H and identifying potential areas of growth for the professionals who work with them. Similarly, there is great need to explore intersectionality and the experiences of youth holding multiple marginalized identities.

Given participants' expressed value and interest in professional development opportunities related to LGBTQ+ youth, training that yields positive outcomes relative to knowledge, skills, and dispositions should be further explored and implemented, particularly among professionals 
Journal of Youth Development | http://jyd.pitt.edu/ | Vol. 16 Issue 5 DOI 10.5195/jyd.2021.1096 4-H Professionals and LGBTQ+ Youth

working in rural settings. Lastly, more research is needed about perceived support for creating welcoming and affirming environments for LGBTQ+ youth and what environmental cues, policies, practices, and aspects of organizational culture impact the level of support experienced by youth-serving professionals.

\section{References}

Barefoot, K. N., Rickard, A., Smalley, K. B., \& Warren, J. C. (2015). Rural lesbians: Unique challenges and implications for mental health providers. Journal of Rural Mental Health, 39, 22-33. (https://doi.org/10.1007/s10597-017-0168-x)

Barr, S. M., Budge, S. L., \& Adelson, J. L. (2016). Transgender community belongingness as a mediator between strength of transgender identity and well-being. Journal of Counseling Psychology, 63, 87-97. (https://doi.org/10.1037/cou0000127)

Benson, P. L., Scales, P. C., \& Syvertsen, A. K. (2011). The contribution of the developmental assets framework to positive youth development theory and practice. In R. M. Lerner, J. V. Lerner, \& J. B. Benson (Eds.), Advances in child development and behavior: Positive youth development research and applications for promoting thriving in adolescence (pp.195-228). Elsevier.

Bradley, E., Albright, G., McMillan, J., \& Shockley, K. (2019). Impact of a simulation on educator support of LGBTQ youth. Journal of LGBT Youth, 16(3), 317-339.

(http://dx.doi.org.prox.lib.ncsu.edu/10.1080/19361653.2019.1578324)

Bregman, H. R., Malik, N. M., Page, M. J., Makynen, E., \& Lindahl, K. M. (2013). Identity profiles in lesbian, gay, and bisexual youth: The role of family influences. Journal of Youth and Adolescence, 42(3), 417-430. (https://doi.org/10.1007/s10964-012- 9798-z)

Brown, D., \& Trusty, J. (2005). Designing and leading comprehensive school counseling programs. Thomson Brooks/Cole.

Diaz, E. M., \& Kosciw, J. G. (2011). Jump-starting youth community leadership: An evaluation of a leadership development program for lesbian, gay, bisexual, transgender, and ally youth. Journal of Youth Development 71 ). (https://doi.org/10.5195/jyd.2012.157)

Doellman, M. (2017). A call to action: The importance of school climate, professional development, and teacher education programs in fostering LGBT supportive educators. In E.A. Mikulec \& P. Iida (Eds.), Queering classrooms: Personal narratives and educational practices to support LGBTQ youth in schools. Information Age.

Farmer, L. B., Welfare, L. E., \& Burge, P. L. (2013). Counselor competence with lesbian, gay, and bisexual clients: Differences among practice settings. Journal of Multicultural Counseling and Development, 41(4), 195-209. (https://doi.org/10.1037/t07178-000) 
Journal of Youth Development | http://jyd.pitt.edu/ | Vol. 16 Issue 5 DOI 10.5195/jyd.2021.1096 4-H Professionals and LGBTQ+ Youth

Fish, J. N., Moody, R .L., Grossman, A. H., Russell, S. T. (2019). LGBTQ youth-serving community-based organizations: Who participates and what difference does it make? Journal of Youth and Adolescence, 48, 2418-2431. (https://doi.org/10.1007/s10964-019-01129-5)

Goldbach, J. T., Tanner-Smith, E. E., Bagwell, M., \& Dunlap, S. (2014). Minority stress and substance use in sexual minority adolescents: a meta-analysis. Prevention Science, 15, 350-363. (http://dx.doi.org/10.1007/s11121-013-0393-7)

Gonzalez, M. (2016). Factors that facilitate and impede school counselor advocacy for and with LGBT students. Journal of Counselor Leadership and Advocacy, 3(2), 158-172. (https://doi.org/10.1080/2326716X.2016.1147397)

Gonzalez, M. (2017). Advocacy for and with LGBT students: An examination of high school counselor experiences. Professional School Counseling, 20(1a), 38-46. (https://doi.org/10.5330/1096-240920.1a.38)

Gonzalez, M., White, A., Vega, L., Howard, J., Kokozos, M., \& Soule, K. (2020). "Making the best better" for youths: Cultivating LGBTQ+ inclusion in 4-H. Journal of Extension, 58(4).

Goodrich, K. M., \& Luke, M. (2010). The experiences of school-counselors-in-training in group work with LGBTQ adolescents. The Journal for Specialists in Group Work, 35(2), 143-159. doi:10.1080/01933921003705966

Hatchel, T., Espelage, D. L., \& Huang, Y. (2018). Sexual harassment Victimization, school belonging, and depressive symptoms among LGBTQ adolescents: Temporal insights. American Journal of Orthopsychiatry, 88(4), 422-430. (http://dx.doi.org/10.1037/ort0000279)

Johns, M. M., Poteat, V. P., Horn, S. S., \& Kosciw, J. (2019). Strengthening our schools to support resilience and health among LGBTQ youth: Emerging evidence and research priorities from the State of LGBTQ Youth Health and Wellbeing Symposium. LGBT Health, 6(4), 146-155. (http://doi.org/10.1089/lgbt.2018.0109)

Katz-Wise, S., \& Hyde, J. (2012). Victimization experiences of lesbian, gay, and bisexual individuals: a meta-analysis. Journal of Sex Research, 49, 142-67. (http://dx.doi.org/10.1080/00224499.2011.637247)

Kearns, L., Mitton-Kükner, J. and Tompkins, J. (2017). Transphobia and cisgender privilege: Pre-service teachers recognizing and challenging gender rigidity in schools." Canadian Journal of Education 40(1): 1-27.

Kokozos, M., \& Gonzalez, M. (2020). Critical inclusion: Disrupting LGBTQ normative frameworks in school contexts. Equity \& Excellence in Education, 53(1-2), 151-164. (https://doi.org/10.1080/10665684.2020.1764881)

Kosciw, J. G., Clark, C.M., Truong, N. L., \& Zongrone, A. D. (2020). The 2019 National School Climate Survey: The experiences of lesbian, gay, bisexual, transgender, and queer youth in our nation's schools. GLSEN. 
Journal of Youth Development | http://jyd.pitt.edu/ | Vol. 16 Issue 5 DOI 10.5195/jyd.2021.1096 4-H Professionals and LGBTQ+ Youth

Larson, R. (2000). Toward a psychology of positive youth development. American Psychologist, 55, 170183. (https://doi.org/10.1037/0003-066X.55.1.170)

Lerner, R. M., Lerner, J. V., Almerigi, J., Theokas, C., Phelps, E., Gestsdóttir, S. Naudeau, S., Jelicic, H., Alberts, A. E., Ma, L., Smith, L. M., Bobek, D. L., Richman-Raphael, D., Simpson, I., Christiansen, E. D., \& von Eye, A. (2005). Positive youth development, participation in community youth development programs, and community contributions of fifth-grade adolescents: Findings from the first wave of the 4-H Study of Positive Youth Development. Journal of Early Adolescence, 25(1), 17-71.

Marx, R. A., Roberts, L. M., \& Nixon, C. T. (2017). When care and concern are not enough: School personnel's development as allies for trans and gender non-conforming students. Social Sciences, 6(1): 1-11.

McCabe, P. C., Rubinson, F., Dragowski, E. A., \& Elizalde-Utnick, G. (2013). Behavioral intention of teachers, school psychologists, and counselors to intervene and prevent harassment of LGBTQ youth. Psychology in Schools, 50(7), 672-688. (https://doi.org/10.1002/pits.21702)

McLaren, S. (2009). Sense of belonging to the general and lesbian communities as predictors of depression among lesbians. Journal of Homosexuality, 56, 1-13. (https://dx.doi.org/10.1080/00918360802551365)

McKee, K. E., \& Bruce, J. A. (2019). Creating inclusive extension programs. Journal of Extension, 576).

Morton, M. H., Dworsky, A., Samuels, G. M., \& Patel, S. (2018). Missed opportunities: Youth homelessness in rural America. Chapin Hall at the University of Chicago.

North Carolina Rural Center. (n.d.). About us. (https://www.ncruralcenter.org/about-us/)

O'Connell, L. M., Atlas, J. G., Saunders, A. L., \& Philbrick, R. (2010). Perceptions of rural school staff regarding sexual minority students. Journal of LGBT Youth, 7, 293-309. (https://doi.org/10.1080/19361653.2010.518534)

Palmer, N. A., Kosciw, J. G., \& Bartkiewicz, M. J. (2012). Strengths and silences: The experiences of lesbian, gay, bisexual and transgender students in rural and small town schools. GLSEN.

Ryan, C., Russell, S. T., Huebner, D., Diaz, R., \& Sanchez, J. (2010). Family acceptance in adolescence and the health of LGBT young adults. Journal of Child and Adolescent Psychiatric Nursing, 23, 205-213. (http://doi.org/10.1111/j.1744-6171.2010.00246.x)

Russell, S. T., \& Fish, J. N. (2016). Mental health in LGBT youth. Annual Review of Clinical Psychology, 12, 465-487. (https://doi.org/10.1146/annurev-clinpsy-021815-093153)

Seelman, K. L., Forge, N., Walls, N. E., \& Bridges, N. (2015). School engagement among LGBTQ high school students: the roles of safe adults and gay-straight alliances characteristics. Children and Youth Services Review, 57, 19-29. (https://doi.org/10.1016/j.childyouth.2015.07.021) 
Journal of Youth Development | http://jyd.pitt.edu/ | Vol. 16 Issue 5 DOI 10.5195/jyd.2021.1096 4-H Professionals and LGBTQ+ Youth

Simons, J. D., Beck, M. J., Asplund, N. R., Chan, C. D., Byrd, R. (2018). Advocacy for gender minority students: Recommendations for school counsellors. Sex Education, 18, 464-478. (https://doi.org/10.1080/14681811.2017.1421531)

Soule, K. E. (2017). Creating inclusive youth programs for LGBTQ+ communities. Journal of Human Sciences and Extension, 5(2), 103-125.

Williams, N. D., Levine, D., \& Fish, J. N. (2019). 2019 Needs assessment: LGBTQ+ youth centers and programs. CenterLink.

Wong, C. F., Schrager, S. M., Holloway, I. W., Meyer, I. H., \& Kipke, M. D. (2014). Minority stress experiences and psychological well-being: The impact of support from and connection to social networks within the Los Angeles House and Ball communities. Prevention Science, 15, 44-55. (http://dx.doi.org/10.1007/s11121-012-0348-4) 